\title{
A MUNDIALIZAÇÃO E OS ESPORTES NA NATUREZA
}

Cleber Augusto Gonçalves Dias

\section{Resumo}

O objetivo deste trabalho é analisar alguns aspectos históricos do processo de formação e desenvolvimento dos esportes na natureza, considerando que essa formação já estava em curso desde o século XIX, ao mesmo tempo em que o período pós Segunda Guerra Mundial representa um importante ponto de inflexão. Assim, a história desses esportes acompanha e se articula a processos sociais mais gerais, tais como, por exemplo, a mundialização.

\section{Palavras-Chave}

História; Lazer; Esportes na natureza.

\section{GLOBALIZATION AND SPORTS IN NATURE}

Cleber Augusto Gonçalves Dias

\begin{abstract}
The objective of this work is to analyze some historical aspects of the formation process and development of the sports in the nature, being considered that this formation already was in course since century XIX, at the same time where the period after Second World War I represents an important point of inflection. Thus, the history of these sports folloies and if it articulates the more general social processes, such as, for example, the globalization.
\end{abstract}

\section{Key-Words}

History; Leisure; Sports in the nature. 


\section{INTRODUÇÃO}

O objetivo deste trabalho é apontar e analisar alguns aspectos históricos do processo de formação e desenvolvimento do campo esportivo que ficaria popularmente conhecido pelo desígnio dos esportes na natureza. Um dos meus argumentos principais é que essa formação já estava em curso desde o século XIX, sendo que o período pós Segunda Guerra Mundial representaria um importante ponto de inflexão. Nessa época, surgiram novas modalidades como o mountain bike, o vôo livre ou o snowboarding, além de algumas outras terem se submetido a profundas alterações quanto aos equipamentos, técnicas e concepções como é o caso do rafting, do surfe ou do montanhismo.

A forma pela qual evolui o hábito de buscar a natureza para a prática esportiva corresponde a uma mudança na dinâmica social em seu conjunto, notadamente no que diz respeito às sensibilidades diante da natureza e ao processo de formação de identidades. Nesse sentido, deve-se dizer que um dos fundamentos primeiros dessas sub-culturas esportivas é o seu hibridismo. Ou seja, o desenvolvimento e a popularização de práticas corporais agrupadas sob a rubrica dos esportes na natureza se constituíram a partir da combinação de técnicas e mesmo de distintas tradições esportivas, como veremos mais a frente.

Esse processo ilustra, acompanha e mesmo dá coesão a uma nova maneira de se formarem símbolos de identificação coletiva, marcado, doravante, pelo intenso fluxo de idéias, imagens e produtos. Desse modo, pretende-se que a análise histórica do esporte jogue luz a processos sociais de caráter mais geral, tais como, por exemplo, a mundialização, tal como tem sido definida por Ortiz (1994).

O processo de massificação simbólica do lazer esportivo na natureza (que é o processo que dá origem à própria noção de esportes na natureza) é o resultado de um encontro entre duas tradições esportivas distintas: uma, de origem européia e que tem o montanhismo como principal representante, e outra, de origem norteamericana, que tem no surfe sua principal expressão. Resultado de dinâmicas históricas diferentes, essas duas tradições vão, num dado momento, se cruzar e influenciar-se mutuamente, gerando um produto híbrido e que pode ser visto como a intercessão dessas duas tradições.

Ao mesmo tempo, é importante salientar que essas duas linhas evolutivas do fenômeno esportivo tinham existências anteriores a esse período. O montanhismo, por exemplo, pode ser visto como o principal precursor do hábito de buscar a natureza para prática esportiva. Esse costume se apresentou de maneira mais visível na Europa, já em meados do século XIX, onde a fundação de clubes de alpinismo fora um marco desse processo. $\mathrm{Na}$ Londres de 1857 fundou-se o primeiro clube alpino que se tem notícia - The Alpine Club (CONFREY, 
2001; HANSEN, 1995). Outras iniciativas análogas foram iniciadas pelo resto da Europa: os clubes alpinos da Suíça e da Itália (1863), o clube alpino alemão (1869), o clube alpino francês (1874) e o clube alpino Belga (1883).

Por outro lado, o surfe é produto de uma outra dinâmica evolutiva do esporte. De origem norte-americana, o surfe difundiu-se maciçamente na esteira do desenvolvimento da contracultura, dos símbolos de identificação da juventude e da indústria do entretenimento norte americana, sobretudo o cinema. Associado ao aparecimento de um novo estilo de vida, que através de uma permanente celebração do prazer, se apresentava menos comprometido com o sistema de valores dominantes - especialmente a ética do trabalho e da produtividade -, o esporte rapidamente se transformou num símbolo de identificação coletiva para a "juventude dourada da Califórnia". Desde então, essa mesma geração de jovens produziu, de dentro das suas garagens empoeiradas, uma infinidade de símbolos de consumo dessa nova cultura esportiva.

Na apresentação do seu filme "Surfing Hollow Days", o diretor Bruce Brow comenta esses acontecimentos.

Em 1961 eu fiz meu quarto filme, "Surfing Hollow Days". O mundo do surf estava mudado. A maioria das pranchas agora eram feitas de fibra, os surfistas viajavam mais (freqüentemente em aviões a jato, que estavam substituindo os turbo-hélices) e Phill Edwards se tornou o primeiro homem a surfar uma onda aparentemente impossível, em um pico que se tornaria conhecido como Pipeline. O mundo ao redor do surf também estava mudando. "Gidget Goes Hawaiian" era um sucesso nos Drive-ins. Dick Dale fazia shows lotados no sul da Califórnia e os Beach Boys - que chegaram a tocar no intervalo de um dos meus primeiros filmes - estavam prestes a tomar de assalto às paradas. $\mathrm{O}$ surf estava virando moda. Pessoas que mal sabiam distinguir uma manobra da outra começaram a se interessar pelo "estilo de vida" do surf. E fazem isso até hoje. Não tenho idéia do que este "estilo de vida" significa. Nossas vidas simplesmente giram em torno do surf. Hoble fazia pranchas. Grubby Clark fazia folhas de espuma de látex usadas na fabricação de pranchas. Eu fazia filmes.

Essas origens distintas fazem com que cada uma dessas modalidades carregue consigo traços culturais que são também distintos. Ou seja, ao passo em que um esporte é uma representação lúdica e simbólica de um dado arranjo social, suas origens diferenciadas tendem a fazer com que cada um deles represente um conjunto de valores que também diferem entre si. Logo, a expressão final dessas representações, isto é, a expressão final do esporte, vai se apresentar de forma diferente, carregando e dramatizando aspectos culturais consideravelmente distintos. Assim, o futebol carrega consigo uma série de elementos simbólicos ligados a sua origem inglesa. Do mesmo modo, o desenvolvimento do futebol no Brasil atribui-lhes usos e formas características e próprias a "cultura brasileira".

Se pensarmos no contexto que deu origem ao montanhismo, fica claro como os valores românticos e vitorianos da Inglaterra do século XIX acometeram esse esporte (Hansen, op.cit.). As noções de amadorismo, 
a preferência pelos clubes como forma de organização, a vocação aristocrática e sua configuração como um símbolo de distinção de classe, refletem ilustrativamente suas origens sociais e que, em alguma medida, acompanham o esporte até os dias de hoje.

No surfe, diferentemente, poderíamos vislumbrar claramente os traços daquilo que Gramsci (2001) chamara de americanismo, qual seja, a radicalização de uma mentalidade empresarial e capitalista, a organização da vida em termos de relações contratuais e assim por diante. Em resumo, o montanhismo respondeu as demandas de uma sociedade moderna, enquanto o surfe, por seu turno, respondeu as demandas de uma sociedade "pós-moderna".

Analisar em profundidade o fenômeno social da busca da natureza com finalidades esportivas exige que se considere o diálogo intersemiótico entre as diversas linguagens esportivas como elementar na formação desse fenômeno social. Lembremos que o impulso inicial para a visitação de áreas naturais dizia respeito a uma nova sensibilidade frente ao mar e também as paisagens de montanha e de florestas (CORBIN, 1989; MACFFARLANDE, 2005; THOMAS, 2001).

O processo Ocidental que deu origem ao reconhecimento de beleza na natureza esteve associado, simultaneamente, a um estímulo de visitação as paisagens montanhosas e marítimas. Ilustrativamente, a personagem Diotima, do filme "A Montanha Sagrada" (1926), interpretada por Leni Riefenstahl, inicia o prelúdio do filme, que tem no montanhismo seu eixo temático principal, dançando para o mar. As belas imagens que se seguem sobre as ondas, concentram-se em enfatizar sua força e violência. A potência da natureza é retratada como uma das fontes de sua beleza. Essa representação é constantemente retomada. $\mathrm{Na}$ verdade, ela perpassa toda a narrativa. O modo como as montanhas são capturas pelas lentes de Arnold Frank concentram-se em exibir as belezas das montanhas, com picos de pedras gastos pelo poder da natureza, como "uma catedral gótica": "imponentes, selvagens e ferozes".

Embora se diga a Diotima que "o mar não pode se casar com a montanha" os impulsos para a mudança de "perspectiva" (no mesmo sentido atribuído por PANOFSKI, 1970) com relação tanto ao mar, quanto à montanha, foram os mesmos. Esse impulso esteve ligado, nos dois casos, ao surgimento da "Doutrina do Sublime", uma doutrina intelectual e estética que celebra o caos, o pavor, a intensidade, o cataclismo, a grandiosidade e a irregularidade. Nesse sentido, pintores holandeses do século XVIII, como Alexander Loutherbourg, começam a retratar regularmente o mar, sobretudo, as tempestades (CORBIN, 1989). Do mesmo modo, dramaturgos, escritores e intelectuais dedicam muitas páginas a descrição de lugares 
“espetacularmente horrendos” como montanhas e penhascos (MAC FARLANE, 2005). Em 1785 Rosseau escreveu:

Preciso de corredeiras, rochas, pinheiros, florestas em decomposição, montanhas, trilhas toscas e precipícios ao meu lado, e que me amedrontem". Na seqüência, segue dizendo, "o estranho, na minha predileção por abismos, é que estes me causam vertigem, sensação que muito me agrada, desde que eu esteja firmemente posicionado" (ROSSEAU, 1785, p. 78).

Diante desse quadro, Robert Macfarlane (2005) conclui:

A mania do sublime constatável no século XVIII não apenas transformou o modo como as pessoas percebiam e descreviam paisagens, mas também o comportamento humano diante das paisagens. Se, no passado, locais inóspitos eram evitados, agora eram procurados como arenas de experiências intensas: lugares onde era possível sentir-se, temporariamente, desnorteado, ou vivenciar a ilusão de alguma ameaça.

Estas paisagens dizem respeito a mares revoltos, bem como íngremes precipícios. Portanto, dizem respeito, numa só palavra, ao um impulso para interagir e confrontar-se com a natureza selvagem. É nesse sentido que o impulso para a busca por interações lúdicas com o mar e a montanha devem ser vistas como integrantes, em termos mais amplos, de um mesmo processo, ambos, desencadeados a partir do século XVIII. O desejo de fruição da natureza nesses termos acaba respondendo a uma mesma dinâmica geral: a constituição da modernidade (CLARK, 2004).

No âmbito especificamente esportivo são duas as modalidades que vão materializar - de maneira um tanto mais óbvia e pioneira - esse sistema de representações: o montanhismo e o surfe. Cada um desses esportes desempenhou papéis inovadores na utilização lúdica de montanhas e de praias, respectivamente. E apesar de pertencerem a diferentes linhas evolutivas do fenômeno esportivo, como já se argumentou, determinados fatores históricos permitirão um encontro, uma combinação e uma fusão, que produz novas modalidades e, por conseguinte, novas representações acerca do que é ser esportivo.

Quer-se destacar, antes de tudo, que a origem do processo de formação dessas práticas será marcada pela combinação de elementos, de tal modo que o hibridismo pode ser visto como um dos traços definidores desse fenômeno social. Inicialmente, essa combinação apareceu com os "esportes de inverno", onde o montanhismo associa-se fortemente ao esqui - apesar de uma certa tendência a autonomização dessas duas práticas, onde cada uma delas chegou a ter, num dado momento, estruturas institucionais próprias (cita-se o caso inglês com o "The Alpine Club" e "Ski Club of Great Britain", fundado em 1903 - a esse respeito c.f. TAILLARD, 2004). É relativamente comum que alpinistas sejam também esquiadores. A maneira como Heinrich Harrer, anotou suas memórias sobre o início da sua carreira esportiva é bastante ilustrativa: "resolvi concentrar-me 
nos dois esportes que mais amava pela sua íntima associação com a natureza - o esqui e a escalada de montanhas". Do mesmo modo, a maneira como as personagens Vigo e "seu amigo" são representadas no já mencionado filme "A Montanha Sagrada", destaca, exatamente, essa dupla dimensão na constituição dos seus estilos de vida: a prática do alpinismo e do esqui.

Anos mais tarde novas combinações se ensaiariam. O mundo das montanhas, com o alpinismo e com o esqui, se encontraria com o mundo dos mares. Preliminarmente, os esquis foram adaptados à água puxando-os com um barco a motor, dando origem ao esqui aquático. Pouco depois, inspirado no surfe, o esqui seria substituído por uma prancha, dando início ao wakeboard. “Adaptando las ideas obtenidas con la práctica del esquí en nieve, surgió el esquí acuático. Más recientemente, la utilización de este arrastre con tablas de surf dio origen al Wakeboard" (GUZMAN, BOYERO, 2001). Na seqüência, com uma influência ainda maior do surfe, a prancha do wake voltaria às montanhas, mas sob o nome de snowboard. Este esporte é classificado por alguns dos seus praticantes, até os dias de hoje, como "surfe na neve".

\begin{abstract}
Foi-se o tempo em que o esqui era a maneira mais emocionante de deslizar sobre a neve. Pelo que se viu nesta última temporada de inverno nos Estados Unidos existe, agora, coisa melhor: o surfe na neve [...] Para todos aqueles cuja principal paixão é colocar os pés sobre uma tábua de surfe, o inverno deixou de ser uma temporada morta. O surfe na neve (snow surfing), ou simplesmente o snurfing foi lançado quando dois snurfers inventaram o winstick - uma prancha de plástico de 1,5 metro de comprimento e cerca de 40 centímetros de largura, coberta de espuma e barbatanas na parte inferior, como uma prancha de surfe [...] a receita para sua prática é exatamente a mesma do surfe: ou seja, subir na tábua e se equilibrar (Veja, 02/04/1975, p. 56).
\end{abstract}

A tecnologia da fabricação de pranchas de snowboard (e de wakeboard) foi incorporada ao surfe possibilitando o nascimento do tow-in: o surfe rebocado ou de ondas gigantes (GO, 2005; jan. 2007). Tem-se também o windesurfe: uma combinação dos fundamentos do surfe e da vela criado nos anos 60 . A criação desta modalidade e dos seus novos equipamentos foi algo feito inicialmente por velejadores que desenvolviam, ao longo da década de 1950, o conceito de free-sail, uma vela feita com equipamentos mais leves e mais manobráveis. Mas foi sob o domínio dos surfistas que o invento ganhou novas possibilidade. Baseados nas manobras do surfe, o windesurfe ganhou maior versatilidade (GO, 2006).

Do mesmo modo, um brinquedo convencional e até bastante desinteressante, quando na mão, ou melhor, nos pés de surfistas, ganhariam vida nova. Até os anos 60, andar de skate não passava de um hábito praticado por surfistas nos dias em que as condições do mar não eram ideais para a sua prática. Com o tempo, o skate ganhou vida própria e se constitui como uma modalidade autônoma e possuidora de símbolos próprios.

Era um sonho essa coisa de poder deslizar no asfalto, imitando surf, fazer uma linha maneira numa onda sem fim. Dar altos cutbacks agachado, encostando joelho com joelho e a bunda 
quase lixando no chão. Naquele tempo andar de skate era o que o surfista fazia quando não dava onda. No meu caso, como era pirralho, skate era o passatempo perfeito pra quando o mar tava muito grande. Ou quando rolava aquele castigo por causa das notas do colégio. Ou seja, eu tinha muito tempo pra andar de skate. Todo surfista andava, e não tinha skatista que não surfasse. Não era outro esporte, era uma coisa só. Ou melhor, surf é que era o esporte. Skate era passatempo [...] O skate veio do surf, e depois virou outra coisa com ídolo, código, moda, comportamento e trilha sonora própria (D’OREY, 2005).

Desse modo, ao próprio surfe, se combinariam novos elementos vindos, curiosamente, do seu desdobramento, o skate. A invenção de algumas manobras na água tinha claramente inspiração naquelas realizadas por skatistas em terra. "No começo os surfistas andavam de skate e imitavam no asfalto o repertório de manobras das ondas - batidinhas, hang five, hang ten, drop, projetadas, cutbacks. Hoje acontece justamente o contrário. O skate evoluiu tanto que agora são os surfistas que copiam os skatistas” (D’OREY, 2005).

Do mesmo modo, o paraglider, um variante do vôo livre e mais conhecido pelo seu nome em francês, parapente. Trata-se de um esporte que nasceu do hábito difundido por alpinistas europeus de descer as montanhas usando pequenos pára-quedas. Em verdade, esse esporte nasceu exatamente da fusão entre o páraquedismo com o montanhismo. Daí, inclusive, a origem do nome francês: "para" do pára-quedismo e "pente" que significa encosta, inclinação.

A utilização da prancha do wakeboard (em si mesmo uma combinação do surfe com o esqui aquático) quando combinada ao parapente originou, em meados dos anos 70, o kitesurfe (GO, 2006). Os modelos mais modernos do kite são apenas aprimoramentos dessa combinação inicial. Emblematicamente, o esporte criado na França pelos irmãos Legaignoux, teve como principal divulgador um norte-americano tido como uma lenda viva do windesurfe: Robby Naish .

É comum vermos praticantes de uma modalidade migrarem para uma outra ou simplesmente praticarem várias delas ao mesmo tempo. Têm-se escaladores que se tornam voadores de asa delta, surfistas que se tornam escaladores, voadores de asa delta que são também surfistas e assim por diante. Por exemplo, Isabelle Patissier, tida como uma das melhores escaladoras francesas é também uma assídua praticante do bungee jumping. Yvon Chouinard, um famoso montanhista é também praticante de surfe e outras modalidades de esporte na natureza (CHOUNARD, 2006). No Rio de Janeiro, tem-se o caso de Bruno Menescal, Heckel Capucci Bastos e Alex Pereira Soares, entre muitos outros escaladores dos anos 70 que, no fim da década, deixaram o montanhismo para se dedicarem à prática da asa delta (WEID, 2006). Tem-se ainda o caso do Pepê, primeiro brasileiro a conquistar o título mundial de asa delta e que praticava também o surfe. 
Não por acaso, "Ricardo Valente" - personagem principal no filme Menino do Rio, de Antônio Calmon (1981) - tinha no surfe "e" na asa delta os dois elementos principais na constituição da sua identidade. O personagem, interpretado por André de Biase, representa uma geração de jovens de classe média que pretendia desfrutar livremente os prazeres da vida através da fruição da natureza, onde práticas esportivas (no plural) das mais diversas se prestavam bem a esse papel.

Esses esportes expressam o resultado de um intenso processo de intercâmbio e de combinações de técnicas, de símbolos ou de materiais entre as diversas modalidades que têm na busca pela aventura na natureza o seu elo de ligação. Dito de outra forma, o processo social de crescente popularização desses esportes resulta de condições históricas que possibilitavam o contato com um universo de informações cada vez mais amplo e diversificado.

Na era da "aldeia global" (um conceito cuja criação coincide com a época de surgimento de muitas dessas modalidades - ver MC LUHAN, 1971a; 1971b), jovens de vários lugares do mundo podiam saber o que pessoas do outro lado do oceano estavam fazendo. A mundialização e as novas tecnologias de comunicação permitiam que um número cada vez maior de pessoas tomasse consciência de que a experiência de grupos diferentes e geograficamente distantes poderia estar sendo semelhante a sua própria.

A criação de uma ceara mundial, onde as fronteiras eram rapidamente atravessadas, permitia um brutal aumento do fluxo, não só de mercadorias no sentido clássico, mas também de idéias e outros "produtos culturais". Dessa maneira, surfistas da Califórnia podiam entrar em contato com as idéias de aventura criadas por alpinistas franceses. Podiam, do mesmo modo, compartilhar valores à distância e buscar novas inspirações para suas próprias aventuras. Também não deve surpreender, portanto, que escaladores que não se conheciam pessoalmente como Royal Robbins, Jean-Pierre Bouvier, Claude Barbeiro ou André Ilha, de lugares tão afastados e diferentes como Estados Unidos, França, Bélgica e Brasil, se encaminhassem, simultaneamente, na direção de concepções semelhantes sobre montanhismo. Nesse caso, concepções que valorizavam o desafio, a dificuldade técnica, o prazer, a ludicidade, a liberdade de movimentos e o contato intenso com a natureza sem intermediação de equipamentos "artificiais" (AMENT, 2003; AUBEL, OHL, 2004; HOIBIAN, 1995), onde tais mentalidades:

Tem relação direta com o que estava acontecendo no mundo inteiro. Isso foi um processo no mundo inteiro e que eu, por ler e estar mais antenado com o que acontecia lá fora nessa época, digamos assim, assumi o papel de divulgador principal aqui. E eu próprio me lancei atrás de buscar fendas pra escalar em móvel [...] estavam nesse processo de levar a escalada livre cada 
vez mais adiante, eliminando os apoios artificiais que existiam em vias antigas e etc (ILHA, 2007).

Nesse sentido, o esporte - fenômeno global por excelência - ia se integrando e se conformando a uma nova ordem mundial desencadeada ao longo dos anos 60. Nesse quadro, não é de se estranhar que os Estados Unidos tenham protagonizado muitas dessas invenções esportivas. Isto porque esse período consolidou, inequivocamente, um deslocamento da hegemonia mundial em direção a esse país.

Convém esclarecer desde já que não me refiro apenas à hegemonia dos capitais e empresas de origem norte-americana, sem dúvida, um fator-chave para o estreitamento da globalização, a ponto de confundir-se com a exportação para todo o planeta do cinema, da televisão e da culinária de um único país. A mudança da oferta e dos gostos dos espectadores que analisamos indicam que o controle econômico dos EUA se associa ao apogeu de certos traços estéticos que não são exclusivos deste país, mas que encontram nele um representante exemplar (CANCLINI, 2005, p. 49).

Para simplificar poderíamos resumir - de maneira até um pouco grosseira - todo esse processo, no âmbito esportivo ou fora dele, como uma espécie de "americanização dos gostos".

Ao estourar a Segunda Guerra Mundial, o predomínio da cultura francesa, em todas as suas facetas, era marcante entre nós. Paris, romanticamente visualizada como em eterna belle époque, era o centro mundial das letras, das artes, dos prazeres... A catástrofe militar a isolar-nos da Europa e a ligar-nos mais de perto aos Estados Unidos, assinalou sob a premência das circunstâncias, mudanças de rumos (CUNHA, 1968, p. 9).

Além desses aspectos, deve-se destacar também o protagonismo juvenil. "A juventude descobria um número cada vez maior de símbolos materiais ou culturais que lhes atribuía identidade [...] passou a existir uma cultura jovem global" (HOBSBAWN, 1998, p. 321). A cultura jovem tornava-se a matriz de uma "revolução cultural": "revolução nos modos e costumes, nos meios de gozar o lazer e nas artes comerciais, que formavam cada vez mais a atmosfera respirada por homens e mulheres urbanos" (HOBSBAWN, 1998, p. 323). O mundo era, desde então, mais jovem do que nunca. Inaugurava-se uma linguagem de busca da satisfação de todos os desejos onde, certamente, os símbolos dos esportes na natureza inserem-se sobremaneira nesse movimento, a que Michel Maffesoli (2003, p. 12) chamou de "juvenelismo", ou seja, "ser jovem na sua maneira de se vestir, de falar, de construir e de cuidar de seu corpo, ou mesmo de pensar e meditar”.

A maneira como cada um desses esportes foi e é utilizado nas estratégias publicitárias permite ter uma idéia mais clara dos sentidos que a prática de cada um desses esportes é capaz de evocar. Já no final dos anos 70, a cervejaria Brahma, por exemplo, realizou uma campanha junto à imprensa escrita que explorava a imagem de alguns desses esportes. "No vôo livre, a Brahma desliza, desce, sobre e flutua nas asas do campeão carioca Patrick Bredl e Marcos Santos. A Brahma também desliza nas pranchas-surf de Daniel Friedman, um dos 
nossos melhores surfistas". Pouco antes, o cigarro Hollywood realizou campanha análoga. Em um desses anúncios via-se a imagem de um windesurfista acompanhada pelos dizeres: "Ação jovem. Participação dinâmica na vida. Presença 'Hollywood King Size Filtro'. O cigarro certo na embalagem vibrante'. Em outra dessas propagandas, pretendia-se uma associação ao universo do vôo livre: "Hollywwod pertence ao mundo das coisas jovens, das idéias novas, do esforço para fazer melhor [...] A embalagem vibrante; o filtro perfeito; a combinação de fumos de sabor inconfundível. Vá com Hollywood, vá para vencer. Ao sucesso com Hollywood". O lançamento de um veículo foi além e associou o próprio nome do carro ao surfe. Desse modo, no final dos anos 70 a Wolkswagem lançava o Passat Surf. Na propaganda se lê: "Pegue a nova onda - Passat Surf: o carro para as pessoas de espírito sempre jovem. Seja qual for a idade. Passat Surf. Uma edição descontraída e esportiva, com a mesma tecnologia que faz do Passat o carro mais avançado do Brasil [...] um carro para as pessoas de espírito jovem como você”.

Aqui, vê-se com mais clareza como a separação dos jovens como uma categoria social específica foi rapidamente percebida pelos fabricantes de bens de consumo, pois a cultura juvenil passava a representar uma massa concentrada de poder de compra.

Os jovens parecem sentir, mais do que nunca, a potencialidade de seus números. Não resta dúvida de que em grande parte isto se deve ao fato de que a máquina publicitária de nossa sociedade de consumo haver dedicado muita atenção aos jovens. Os adolescentes dispõem de um enorme volume de dinheiro e gozam de muito lazer; era inevitável, assim, que passassem a constituir um mercado especial. Foram adulados, utilizados, idolatrados e tratados com uma deferência quase nauseante (ROSZAK, 1972, p. 38).

A análise do fenômeno esportivo vai nos exibindo, em suma, a maneira como a partir do término da Segunda Guerra Mundial, e ainda mais intensamente a partir dos anos 60, identidades se tornaram fluídas, instáveis, cosmopolitas, híbridas e, fundamentalmente, teriam no ato do consumo seu principal gerador, onde o esporte amplificava o alcance dessas representações dando-lhe materialidade. Dessa maneira, a compreensão da forma pela qual o fenômeno esportivo foi se re-configurando, ajuda-nos a perceber com mais clareza outras esferas de re-significação do jogo social mais amplo.

\section{REFERÊNCIAS}

AUBEL, O.; OHL, Fabien. The denegation of the economy: the example of climbing in France. Internacional Review for the Sociology of Sport., v. 39, n. 2, 2004.

AMENT, P. Royal Robbins: el espiritu de una época. Madrid: Desnível, 2003. 
CANCLINI, N. Consumidores e cidadãos. 5. ed. Rio de Janeiro: Ed. da UFRJ, 2005.

CHOUINARD, Y. Que mi gente vaya a hacer surf. Barcelona: Desnível, 2006.

CLARK, T. J. A pintura da vida moderna. São Paulo: Companhia das Letras, 2004.

CONEFREY, M.; JORDAN, T. Mountain men: tall tales and high adventure. London: Boxtree, 2001;

CORBIN, A. Território do vazio: a praia e o imaginário social. São Paulo: Companhia das letras, 1989.

D’OREY, F. Skate é surfe sem tubo. FLUIR, n. 241, nov. 2005.

CUNHA, R. V. da. França: crise e esperança. Jornal do Brasil, Caderno especial, a guerra de nossos dias.

Rio de Janeiro, 01 set. 1968. p. 9

GO Outside. Peixe Grande. Set. 2005.

. Febre de pranchas. Mar. 2006.

. Vai encarar? tow-in. Jan. 2007.

G., A. Cadernos de cárcere. Rio de Janeiro: Civilização Brasileira, 2001. v. 4.

GUZMÁN, K. L.; B., P. Nuevas tendencias deportivas: deportes de sliz. Lecturas. Buenos Aires, v. 6, n. 30, 2002. Disponível em: http://www.efdeportes.com. Acesso em:

HANSEN, P. Albert Smith: the Alpine Club, and the Invention of Mountaineering in Mid-Victorian Britain. Journal of British Studies, v. 34, 1995.

HARRER, H. Sete anos no Tibet. Porto Alegre: L\&PM, 1999.

HOBSBAWM, E. Era dos extremos: o breve século XX 1914- 1991. São Paulo: Companhia das Letras, 1998.

HOIBIAN, O. De l'alpinisme à l'escalade libre: l'invention d'un style? Revue STAPS, Paris, v. 16, n. 36, 1995.

ILHA, A. Entrevista ao autor, nov. de 2007.

MACFARLANE, R. Montanhas da mente: história de um fascínio. Rio de Janeiro: Objetiva, 2005.

MAFFESOLI, M. O instante eterno: retorno do trágico nas sociedades pós-modernas. São Paulo: Zouk, 2003.

MCLUHAN, M. Os meios de comunicação como extensões do homem. São Paulo: Cultrix, 1971 a.

. Guerra e paz na aldeia global. São Paulo: Record, 1971 b.

ORTIZ, R. Mundialização e cultura. São Paulo: Brasiliense, 1994.

PANOFSKY, E. A perspectiva como forma simbólica. Lisboa: Edições 70, 1999.

ROSZAK, T. A contracultura. 2. ed. Petrópolis, Vozes, 1972.

TAILLAND, M. L'Alpine Journal: une revue savante entre maintien de la tradition et tentation du modernisme (1863-2004). La Garde, n. 10, p. 29-49, 2004.

THOMAS, K. O homem e o mundo natural: mudanças de atitude em relação às plantas e aos animais 15001800. São Paulo: Companhia das Letras, 2001. 
SURFE na neve. Veja, São Paulo, p. 56. abr. 1975.

WEID, J. P. Von der. Horizontes verticais. Rio de Janeiro: J. P. Weid, 2006. 


\section{Cleber Augusto Gonçalves Dias}

\section{UNICAMP}

\section{Referência do artigo:}

\section{ABNT}

DIAS, C. A. G. A mundialização e os esportes na natureza. Conexões, v. 6, n. 1, p. 54-66, 2008.

\section{APA}

Dias, C. A. G. (2008). A mundialização e os esportes na natureza. Conexões, 6(1), 54-66.

\section{VANCOUVER}

Dias CAG. A mundialização e os esportes na natureza. Conexões, 2008, 6(1): 54-66. 